\title{
Chemical causes of concrete degradation
}

\begin{abstract}
The durability of reinforced concrete structures depends on their behavior in relation to the climatic and environmental conditions that exist in the environments in which they are built. These structures are often subject to a permanent process of physical and chemical degradation as a result of external aggression. In this context, this paper presents the different chemical causes of concrete degradation such as carbonation, alkali-reaction and sulphate reactions. The diagnosis and repair techniques of the infected concrete have also been developed.
\end{abstract}

Keywords: chemical degradation, carbonation, alkali-reaction, sulphate reaction, diagnosis, repair
Volume 4 Issue I - 2018

\author{
Malek Jedidi, ${ }^{1,2}$ Omrane Benjeddou' \\ 'Department of Civil Engineering, Higher Institute of \\ Technological Studies of Sfax, Tunisia \\ ${ }^{2}$ National Engineering School of Tunis, University Tunis El Manar, \\ Tunisia
}

Correspondence: Malek Jedidi, Department of Civil Engineering, Higher Institute of Technological Studies of Sfax, B.P.88, 3099 Sfax, Tunis, Tunisia, Tel 216-982-586-8I, Fax 216-7443|4-25, Email malekjedidi@yahoo.fr

Received: November 23, 2017 | Published: January 31, 2018
Abbreviations: AGR, alkali-granulate reaction; ESR, either external sulfate reaction; ISR, internal sulfate reaction

\section{Introduction}

A concrete structure must withstand over time the various attacks or stresses to which it is subjected, as well as various actions such as wind, rain, cold, heat, the environment while maintaining its aestheticism. It must satisfy, at a constant level, the needs of users during its service life. The notion of durability of a structure results in a set of technical specifications based on direct or indirect test methods, experience and recommendations for implementation, manufacture and maintenance. In fact, it is now possible to define sustainability objectives and to choose concrete characteristics precisely according to the aggressiveness of the environment in which the structure is located and to optimize its characteristics in order to adapt them to the duration desired service. The specifications concern the nature and minimum cement dosage, the minimum compactness, the maximum value of the Water/ Cement ratio, the minimum encapsulation of the reinforcements and the maximum chloride content in the concrete. The diagnosis of the state of conservation of a reinforced concrete structure makes it possible to characterize the origin and the extent of the possible disorders. In general, this diagnosis follows a detection of disorders, but it is also requested in various settings, such as renovation work or regular inspections. A prior inspection of the structure makes it possible to make assumptions about the possible causes of the disorders, and thus to specify the operations to be performed, taking into account the operation of this structure. The mechanical functioning of the different parts of a structure is a very important point to consider.

Indeed, if the phenomenon that causes deterioration of the base concrete is not controlled or if its diagnosis is incorrect, it is very likely that this mechanism of degradation also affects the repair concrete. An incorrect identification of the source of the problem then results in costly, unsuccessful and especially recurrent interventions, which is certainly not interesting from the point of view of the sustainability of the works and budgets, sometimes limited, managers. Concretes can be confronted with chemically aggressive environments that cause their degradation such as carbonation, alkalireaction and sulphate reactions. ${ }^{1,2}$ The natural concrete carbonation depends simultaneously on the materials' characteristics and the surrounding environment and it is associated with $\mathrm{CO}_{2}$ diffusion in concrete. It causes the reinforcement de passivation leaving the steel susceptible to corrosion. ${ }^{3-6}$ The most common repairs to concrete structures are either wet or dry process concrete, or formwork with or without concrete overlay, or more recently self-leveling concrete. This innovative technique is currently the subject of all intentions. This material is so fluid and lends itself to the most complex forms without being vibrated. The repair of a concrete element that usually involves two very different materials, where the placement of a young concrete on an older concrete support causes different types of problems, both physico-chemical and mechanical, related to the broad compatibility of the two materials in contact.

\section{The different chemical causes of concrete degradation}

\section{Carbonation}

Definition: The carbonation is a chemical phenomenon linked to the emission of carbon dioxide into the atmosphere. ${ }^{7-10}$ It is pathology of reinforced concrete which, with the time, reaches layers more and more important. It degrades the reinforced concretes and is in particular responsible for the exposure of their steel frames. Carbon dioxide $\mathrm{CO}_{2}$ enters gaseous form in concrete. It causes a reaction, called carbonation, with interstitial water. The carbonation front advances progressively from the facing. It converts calcium hydroxide $\mathrm{Ca}(\mathrm{OH})_{2}$ "hydrated lime", which is a base, and which gives the water in the pores of concrete a high $\mathrm{pH}$ (between 12.5 and 13), carbonate $\left(\mathrm{CaCO}_{3}\right)$. This carbonation front lowers the $\mathrm{pH}$ of the interstitial solution from 13 to about $9 .{ }^{11}$ This degrades the passivation of the reinforcements. From a chemical point of view this reaction is as well:

$$
\mathrm{CO}_{2}+\mathrm{Ca}(\mathrm{OH})_{2} \Leftrightarrow \mathrm{CaCO}_{3}+\mathrm{H}_{2} \mathrm{O}
$$




\section{Carbonation process}

When curing concrete and after evaporation of water, the pores partially fill with air. The atmosphere currently contains about 0.33 $\mathrm{ml}$ of carbon dioxide $\left(\mathrm{CO}_{2}\right)$ per liter of air. The $\mathrm{CO}_{2}$ is then likely to diffuse through the gaseous phase of the cement. It can be seen that the cement is totally saturated with water and carbonates only on their boundary layer because of an immediate clogging of the pores by formation of calcite. Carbonation in concrete can be divided into three main stages:

I. Diffusion of carbon dioxide in concrete: The alkalinity of new concrete is at a $\mathrm{pH}$ of 12 to 13 . This high alkalinity protects the metal reinforcement of the concrete against oxidation. On the other hand, the penetration of carbon dioxide $\left(\mathrm{CO}_{2}\right.$ decreases the $\mathrm{pH}$ of the concrete (Figure 1A)

II. Dissolution of $\mathrm{CO}_{2}$ in water: Chemical chain reactions requiring the presence of: concrete, steel, $\mathrm{CO}_{2}$ and water. This chemical reaction called "carbonation" (Figure 1)

III. Chemical reaction between dissolved carbon dioxide and $\mathrm{Ca}(\mathrm{OH})_{2}$ calcium hydroxides: The oxidation thus provoked brings about an appreciable increase in its volume, so much so that the concrete begins to crack and burst (Figure 1C) and (Table 1).

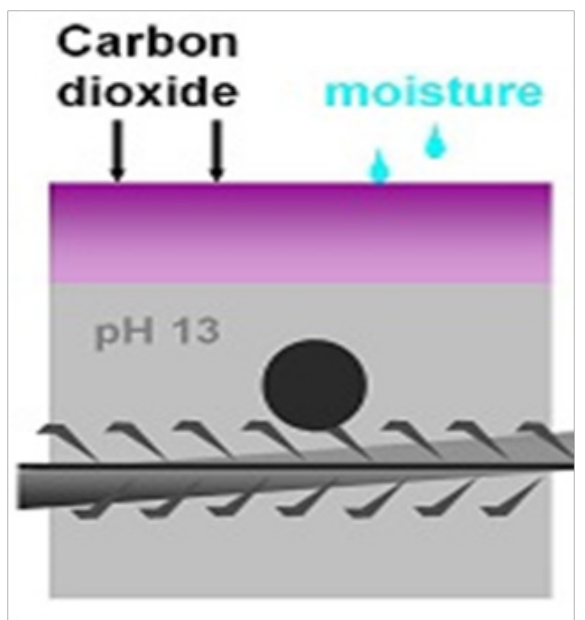

Figure IA Diffusion of carbon dioxide in concrete.

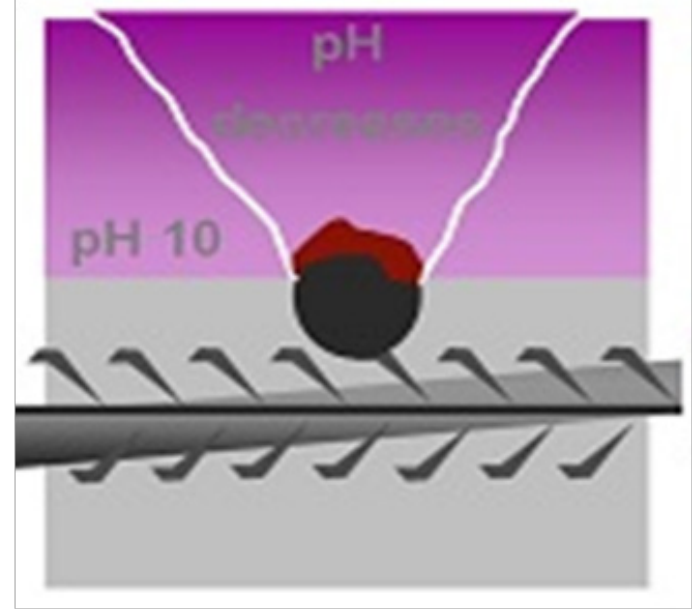

Figure IB Dissolution of $\mathrm{CO} 2$ in water.

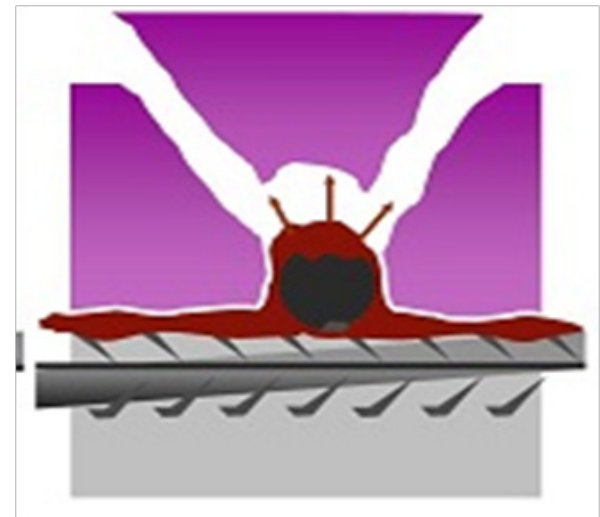

Figure IC Chemical reaction between dissolved.

Figure I Damage due to the reinforcement corrosion process.

Table I Factors that influence the rate of carbonation of concrete

\begin{tabular}{ll}
\hline Factor & Influence \\
\hline W/C ratio (water/cement) & $\begin{array}{l}\text { The lower the ratio, the lower the carbonation rate. } \\
\text { Cement concretes with secondary constituents (slags, fly ash, pozzolans) carbonate faster than Portland cement } \\
\text { concretes. } \\
\text { Type of cement }\end{array}$ \\
$\begin{array}{l}\text { An increase in dosage decreases the carbonation depth at a given time. } \\
\text { Cement dosage }\end{array}$ \\
$\begin{array}{l}\text { A good cure reduces the rate of carbonation, because the concrete will be more compact and the hydration of } \\
\text { the cement increased. }\end{array}$ \\
Humidity & $\begin{array}{l}\text { The carbonation rate is maximum for a humidity of between } 40 \% \text { and } 80 \% . \\
\text { Temperature }\end{array}$ \\
\hline
\end{tabular}




\section{Diagnosis and treatment of carbonation}

The purpose of a diagnostic is to find the cause of the degradation. Destructive and Non-destructive methods of investigation can be used for the control of certain characteristics of the concrete. ${ }^{12}$ The following tests can be performed (Figure 2):

I. The visual inspection which aims to search for all visible cracks and degradations

II. The location of the reinforcement and the determination of the reinforcement coating using a photometer (pachometer)
III. The measurement of the hardness with the sclerometer

IV. The measurement of the carbonation depth by spraying a $\mathrm{pH}$ indicator, phenolphthalein. The coloring in pink represents the non-carbonated zone, the colorless part the carbonated zone

V. Measurement of chloride content

VI. The cabonation depth test is determined according to the RILEM CPC $18^{13}$ using the spray-based solution technique with $1 \%$ phenolphthalein mixed in $70 \%$ ethyl alcohol. The solution is sprayed onto the concrete surface which has been cleaned for dust and loose particles.
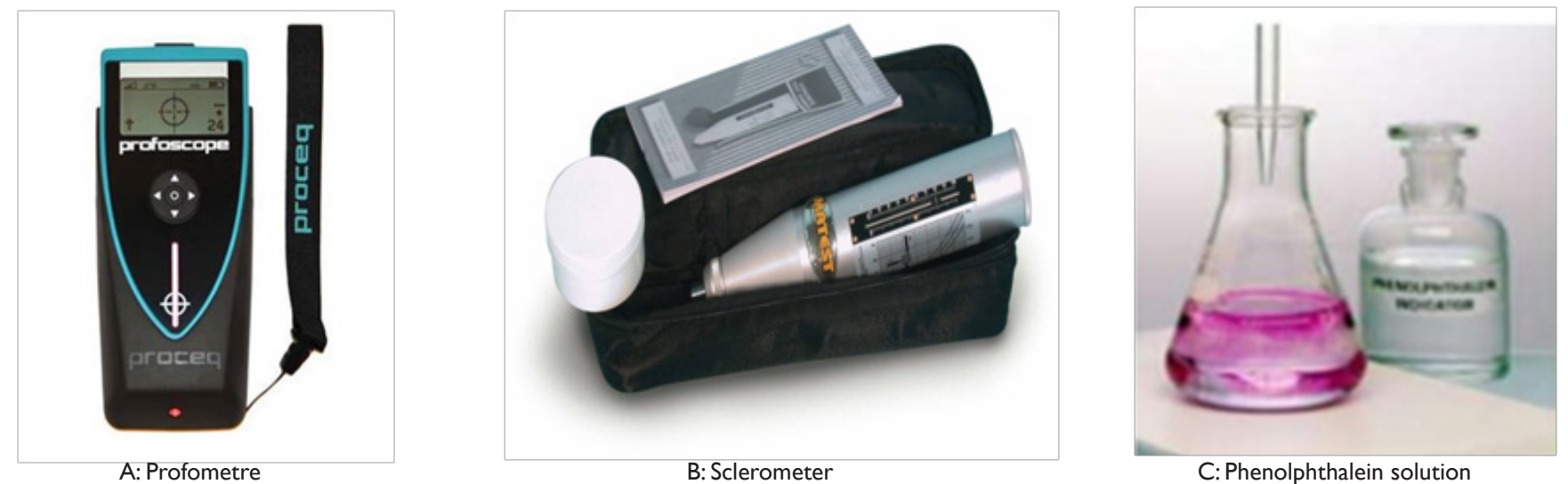

Figure 2 Diagnostic equipment.

The advance of concrete carbonation is influenced by the exposure conditions and environmental conditions. ${ }^{14-16}$ After developing an adequate diagnosis, the repair can begin. It is essential to refer to regulations and standards, and the technical specifications contained in the technical data. The perimeter of the surface to be repaired must have sharp edges for the cleanliness of the repair. Degraded concrete areas must be removed to find the sound surface of the concrete. A jackhammer is usually used. After removal of friable parts and clearance of reinforcement, brushing and scraping to remove rust can occur (Figure 3A). A rust inhibitor is possible and can be applied. In the event of a significant reduction in the section of the steel, it will be necessary to strengthen or replace. The minimum overlap thickness of the reinforcement shall be respected in all cases as this is an important factor for its protection. After the reinforcement treatment we can apply the repair concrete (Figure 3B). The type of concrete required is chosen carefully according to the desired repair character. The chosen repair product will be applied once the surfaces have been thoroughly cleaned. An application of the mortar in successive layers of 5 to 50 $\mathrm{mm}$ maximum must be carried out by compressing it strongly using a trowel (Figure 3C). It is important to properly tamp the mortar around the reinforcement bars to avoid air inclusions. At the end, a traditional float of the repaired parts was realized (Figure 3D). A final painting with concrete protection property against carbonation can also be applied.

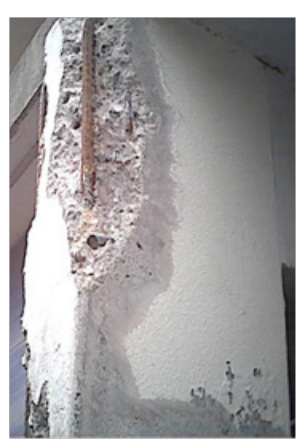

A

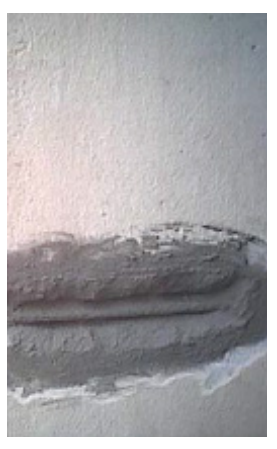

B

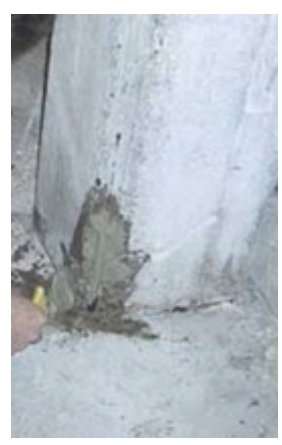

C

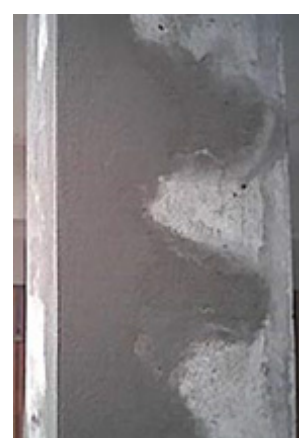

D

Figure 3 Treatment of carbonation:

A:Treatment of reinforcement

B: Repair concrete application

C: Mortar application using a trowel

D:Traditional float of repaired parts. 


\section{Alkali-reaction of the concrete}

Definition: The alkali-reaction or the alkali-granulate reaction (AGR) is a chemical reaction between reactive aggregates and the alkalis contained in the cement. ${ }^{17,18}$ This reaction produces an expansion inside the concrete which will create tensions, then swelling and cracks (Figure 4). There are three types of reaction:

I. Alkali-carbonate reactions: This reaction is created with aggregates composed of clay dolomite and fine-grained limestone with inclusion of clay minerals, the mechanism of swelling is related to the water absorption of clays

II. The alkali-silicate reaction: it is similar to the alkali-silica reaction but of slower kinetics, it is very rare and will generally occur a few decades after the concrete element has been manufactured

III. Alkali-silica reaction: This is the most common type of reaction that usually occurs within a few years after the concrete element is manufactured.
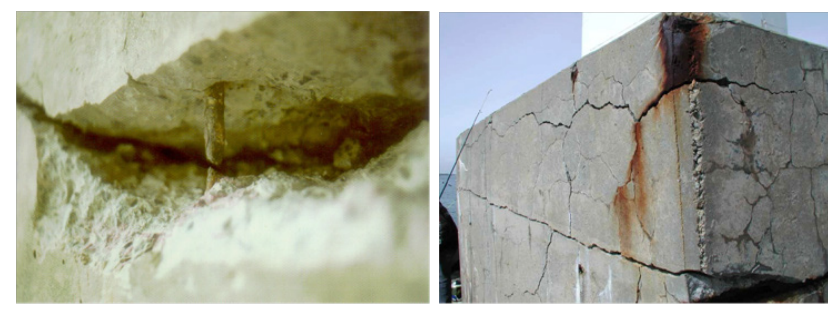

Figure 4 Disorders caused by the Alkali-reaction of concrete.

\section{Prevention against alkali-reaction phenomena}

The principle of the preventive approach consists in not being in a situation in which the three conditions necessary for the initiation of the reaction are simultaneously present. It is therefore necessary to avoid the conjunction of the three factors: water (relative humidity condition greater than $80-85 \%$ ), amount of alkaline in the large concrete and reactive silica (presence of reactive aggregates). The prevention method is divided into two stages. It is based on the environment (Table 2) and the type of structure (Table 3 ) to determine the level of prevention to be achieved A, B or C (Table 4), and then verify that the formulation intended for concrete is satisfactory. It thus makes it possible to implement preventive recommendations adapted to the importance of the structure and its environment.

The recommendations to be applied depend on the level of prevention

Level A: No specific specifications;

Level B: Six possibilities of acceptance of the concrete formula;

Level C: Non-reactive aggregates (PRP granulates under conditions).

Table 2 Types of environment. ${ }^{19}$

\begin{tabular}{ll}
\hline Classes & Environment \\
\hline I & Dry or slightly humid (humidity below $80 \%$ ) \\
2 & Humidity greater than $80 \%$ or in contact with water \\
3 & Hygrometry above $80 \%$ and with gel and flux \\
4 & Marine \\
\hline
\end{tabular}

Table 3 Types of structures. ${ }^{19}$

\begin{tabular}{lll}
\hline $\begin{array}{l}\text { Types of } \\
\text { structures }\end{array}$ & Risk level & Examples of structures \\
\hline I & $\begin{array}{l}\text { Risks of occurrence of } \\
\text { weak or } \\
\text { acceptable disorders }\end{array}$ & $\begin{array}{l}\text { Non-carrying elements, Most } \\
\text { precast concrete products }\end{array}$ \\
II & $\begin{array}{l}\text { Risks of occurrence of } \\
\text { intolerable disorders }\end{array}$ & $\begin{array}{l}\text { Non-carrying elements, Most } \\
\text { civil engineering structures }\end{array}$ \\
III & $\begin{array}{l}\text { Risks of occurrence of } \\
\text { unacceptable disorders }\end{array}$ & $\begin{array}{l}\text { Tunnels, dams, bridges, } \\
\text { viaducts }\end{array}$ \\
\hline
\end{tabular}

Table 4 Risk level. ${ }^{19}$

\begin{tabular}{llcll}
\hline Types of structures & \multicolumn{4}{l}{ Exhibition Classes } \\
\hline & I & 2 & 3 & 4 \\
I & A & A & A & A \\
II & A & B & B & B \\
III & C & C & C & C
\end{tabular}

\section{Disorders due to the alkali-reaction}

Figure 5 shows the alkali-reaction disorders that may occur generally at varying time intervals of two to ten years or more. The openings of the cracks are variable according to the progress of the reactions. They can be a few tenths of a millimeter for a small cracking and reach a few millimeters for cracking with large meshes. Crack openings can be measured using a fissurometer. The principle is to place the fissurometer over the crack and slide it until a graduated line exactly superimposes over the width of the crack (Figure 6).

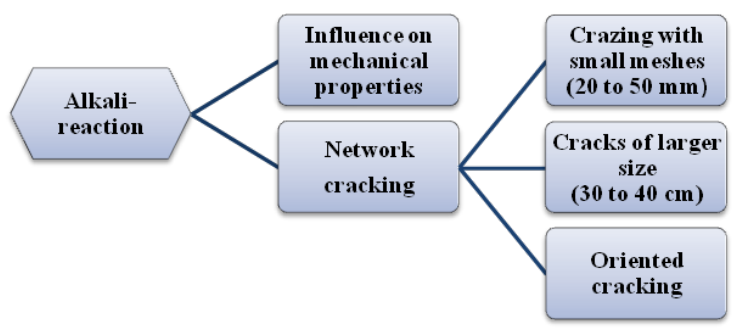

Figure $\mathbf{5}$ The alkali-reaction disorders.

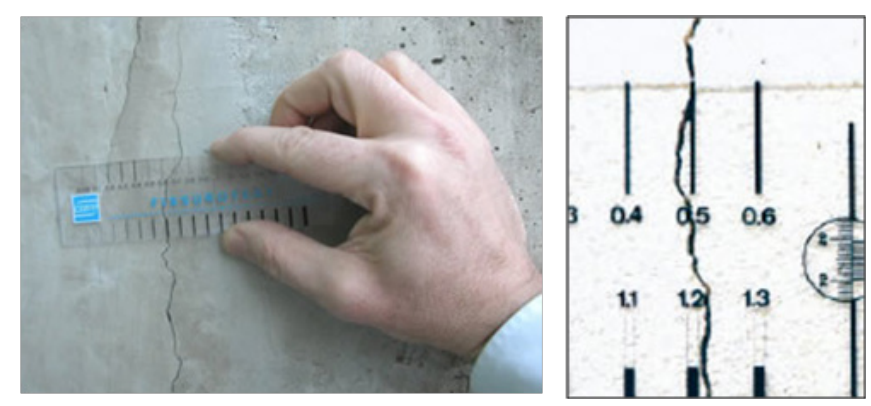

Figure 6 Measuring the thickness of a crack by a fissurometer.

\section{Repair of disorders due to the alkali-reaction}

There are some methods that can slow the evolution of reactions or stop the evolution of disorders such as: 
I. Injection of epoxy resins into the cracks to prevent water from entering the interior of the cracks but will not protect the rest of the cladding. Indeed, after a while, cracks can reopen or new ones can be created nearby.

II. Avoiding disorders caused by alkali-aggregate reactions is to stock up on non-reactive sand and granulate, but this can sometimes cause an economic and ecological problem because the closest non-reactive aggregates are often very far away.

III. Use of cement with mineral additions. Indeed, the introduction of mineral additions into the cements can reduce or cancel the expansion caused by the alkali-reaction. Mixtures of two supplementary cementing materials with Portland cement are very effective in preventing deterioration due to alkali-reaction. ${ }^{20}$

IV. Opting for a W/C ratio below 0.5 has the effect of increasing the resistance, while reducing the permeability and porosity of the concrete, which will protect it against water and possible expansion efforts of the reaction.

V. Prevent the arrival of moisture within a structure. Drainage with a good seal can definitely solve this problem, but also a good disposition of the joints of the structure is important.

VI. Pay close attention to the laying of reinforcement and respect the minimum thickness of the coating, as a steel bar emerging from the concrete will corrode and create an opening that will bring water into the concrete.7. Avoid segregation when placing concrete and treat concreting with concrete of good workability.

\section{Sulphate reactions}

Definition: Sulphate attacks have a major problem of concrete durability. They destroy the concrete by degrading its mechanical properties. These include sulphate reactions that cause swelling in concrete and crack networks. The sulphate attack is associated with the precipitation of secondary sulphates, a significant expansion and the chemo-mechanical deterioration (changes in properties, cracks, loss of strength and cohesion). This can lead to the ruin of the cementitious material, more or less long term depending on the attack (nature, content and concentration of sulphates in contact) and the cement used (type and W/C ratio).

\section{Types of sulphate reactions}

Sulfate reactions are categorized into two broad classes based on the origin of source of sulfate (Figure 7), as either external sulfate reaction (ESR) or internal sulfate reaction (ISR).

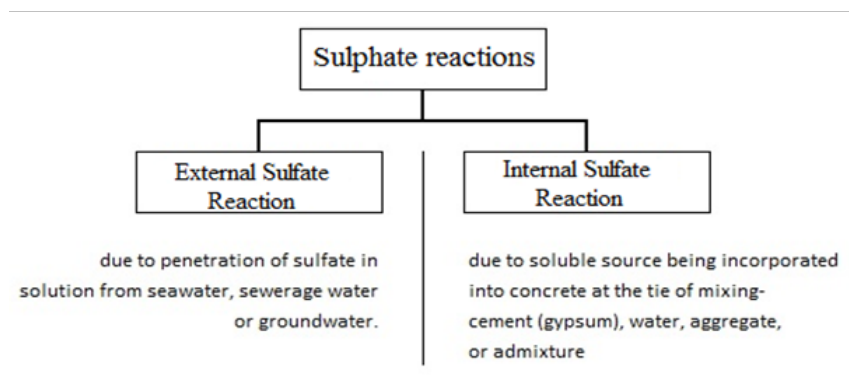

Figure 7 Types of sulfate reactions.

\section{Internal sulphate reactions ISR}

The internal sulphate reaction ISR phenomenon has been encountered in several countries in prefabricated concrete railway ties that have undergone heat treatment. These countries include Finland in $1987,{ }^{20}$ Germany in $1989,{ }^{21}$ Australia in $1992,{ }^{22}$ the United States in $1995^{23}$ and more recently Sweden in $2004 .{ }^{24}$ The RSI phenomenon has also been identified in some prefabricated concrete elements. In particular, this reaction has been demonstrated in a US parking staircase, ${ }^{25}$ in prestressed girders and gutters in the United Kingdom, ${ }^{26}$ in a stadium stand in the United States ${ }^{27}$ and in fiberglass roofscement in Italy. ${ }^{28}$ In the majority of these prefabricated elements, the disorders were observed in less than ten years after construction. The ISR is a pathology of cementitious materials related to the formation of a hydrate which is ettringite. Ettringite is a mineral species containing sulphates, It is a calcium trisulfoaluminate hydrated in cement notation resulting from the reaction between the calcium aluminates and the gypsum. An ettringite layer is then formed around the anhydrous cement grains. Figure 8 gives the three conditions that must be met to trigger the ISR. The ISR are characterized by surface cracks that appear after several years of exposure to severe conditions characterized by high humidity (Figure 9). This rare phenomenon can occur only in damp environments, in massive cast-in-place concrete parts in summer or on heat-treated concrete parts.

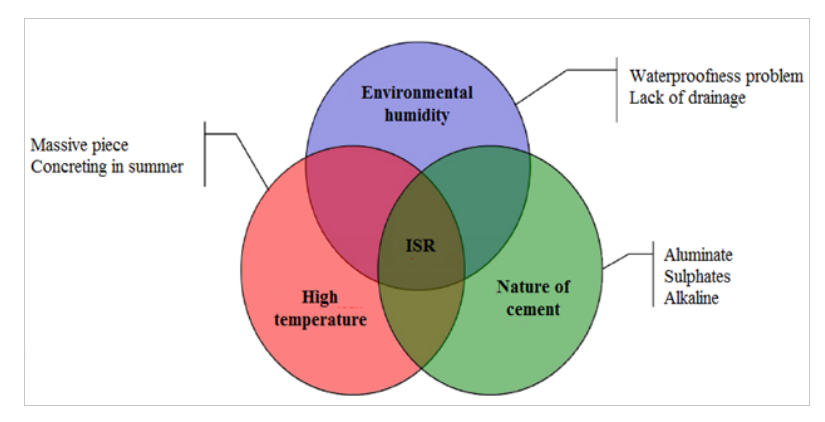

Figure 8 Conditions for the ISR.
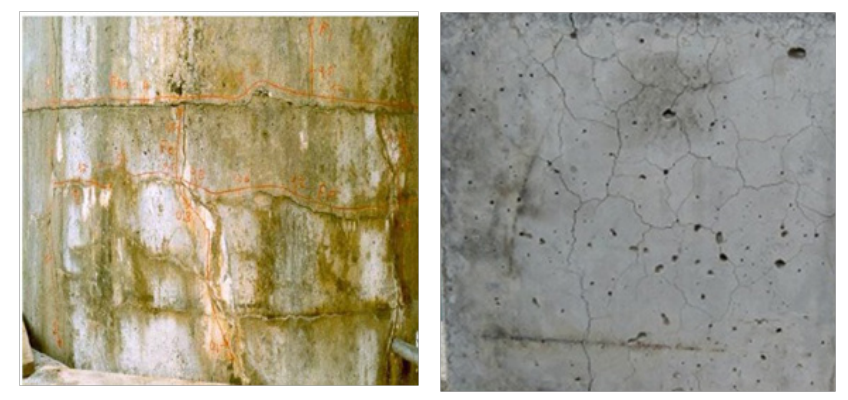

Figure 9 Consequences of the ISR: surface cracking.

\section{External sulphate reactions ESR}

External sulfate reaction ESR is a chemical breakdown mechanism where sulfate ions from an external source attack components of the cement paste. It occurs when a cementitious material is in direct contact with a sulphate source, such as in soils, groundwater, seepage water, acid rain (sulfuric acid) related to industrial pollution atmospheric (Figure 10). The often massive formation of gypsum and ettringite formed during the ESR may cause concrete to crack and scale. However, both laboratory studies and examinations of field concrete show that external sulfate attack is often manifested, not 
by expansion or cracking, but by loss of cohesion and strength. The ESR essentially depends on the following parameters: The quality of the concrete, namely the composition of the cement, the method of manufacture, the cure, the state of damage of the concrete before the attack. The exposure on the site namely the concentration of $\mathrm{SO}_{4}{ }^{2-}$ and its distribution in the soil, moisture, transport opportunities.

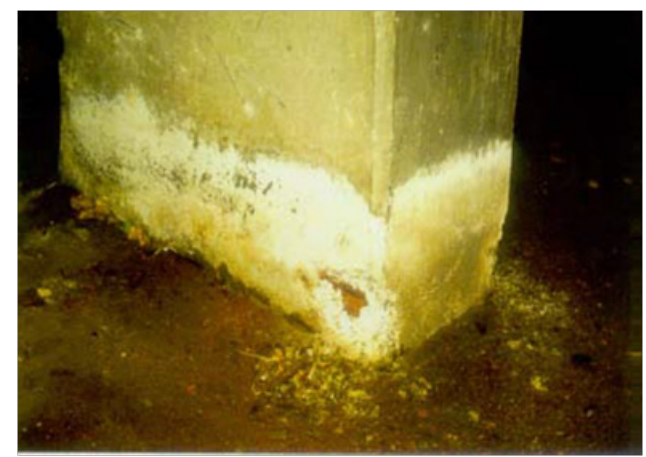

Figure 10 Consequences of the ESR: formation of ettringite.

\section{Prevention of disorders related to ISR}

The precautions to be implemented depend on a level of prevention defined for each part of a potentially "critical" structure. They take into account: a. The category of structures;

b. The environmental actions to which the parts of the structures concerned will be subjected during the period of use of the structure;

c. The thermal conditions of the concrete during its implementation and during its hardening.

The recommendations concern only parts of large concrete structures in contact with water or in a humid environment. These are massive pieces or "critical" for which the heat released during the hydration of the cement (the setting and the hardening of the concrete generate a release of heat due to the exothermic reactions of hydration) is little evacuated to the outside, which leads to a significant rise in the temperature at the heart of the concrete. The principle of the preventive approach is to identify the parts of structures likely to be subjected to the phenomenon of ISR, then to define a level of prevention necessary according to the category of the work or the part of work and the exposure classes specific to the ISR, reflecting the environment in which the concrete is located. At each level of prevention (As, Bs, Cs, Ds) there is a level of caution to apply (Table 5). It is then necessary to implement for each part of work concerned the precautions adapted to each level of prevention.

Table 5 Summary of the precautions to be applied to the ISR

\begin{tabular}{|c|c|c|c|}
\hline $\begin{array}{l}\text { Level of } \\
\text { prevention }\end{array}$ & $\begin{array}{l}\text { Maximum temperature } \\
\text { of concrete } T_{\max }\end{array}$ & $\begin{array}{l}\text { Limit temperature of } \\
\text { concrete } T_{\text {limit }}\end{array}$ & $\begin{array}{l}\text { Conditions to be respected if temperature between } \\
T_{\max } \text { and } T_{\text {limit }}\end{array}$ \\
\hline AS & $85^{\circ} \mathrm{C}$ & - & - \\
\hline BS & $75^{\circ} \mathrm{C}$ & $85^{\circ} \mathrm{C}$ & $\begin{array}{l}\text { - Mastery of heat treatment or Suitable cement or - } \\
\text { Performance test }\end{array}$ \\
\hline CS & $70^{\circ} \mathrm{C}$ & $80^{\circ} \mathrm{C}$ & $\begin{array}{l}\text { - Mastery of heat treatment or Suitable cement or - } \\
\text { Performance test }\end{array}$ \\
\hline DS & $65^{\circ} \mathrm{C}$ & $75^{\circ} \mathrm{C}$ & $\begin{array}{l}\text { - Suitable cement; Validation of the formulation by a } \\
\text { laboratory; Independent expert in ISR }\end{array}$ \\
\hline
\end{tabular}

\section{Conclusion}

The present paper has presented the different chemical causes of concrete degradation as well as the diagnosis and repair techniques of the infected concrete. The following conclusions have been drawn from the investigation:

I. The carbonation causes problems of durability and resistance on reinforced concrete structures. The steel bars, supposed to guarantee this resistance, swell under the effect of the corrosion and burst the concrete of coating.

II. The measurement of the carbonation depth can be carried out using the phenolphthalein solution. The pink color represents a non-carbonated zone while the colorless portion is a carbonated zone.

III. The alkali-reaction of concrete is a chemical reaction between reactive aggregates and the alkalis contained in the cement. This reaction produces an expansion inside the concrete which will create tensions, then swelling and cracks.

IV. The alkali-reaction of the concrete causes a $30-50 \%$ reduction of these mechanical properties as well as irregular cracks of all shapes.

V. Sulphate attacks are a major sustainability problem that destroys concrete by degrading its mechanical properties and causing swelling and crack networks.

\section{Acknowledgements}

None.

\section{Conflicts of interest}

The author declares there is no conflict of interest.

\section{References}

1. Mehta PK. Reducing the environmental impact of concrete: concrete can be durable and environmentally friendly Concr Int. 2001. p. 61-66.

2. Monkman S, Mac Donald M. Carbon dioxide upcycling into industrially produced concrete blocks. Construction and Building Materials. 2016;124:127-132.

3. Possan E. Modeling of Carbonation and the Service Life Prediction of 
Concrete Structures at an Urban Environment. Doctorate Thesis in Civil Engineering. Federal University of Rio Grande do Sul, Porto Alegre, Brazil. 2010 .

4. Neville AM. Properties of Concrete. $5^{\text {th }}$ ed. Pearson, Harlow, UK. 2011.

5. Parrott LJ. A Review of Carbonation in Reinforced Concrete. Building Research Establishment, Waterford, UK. 1987.

6. Pasupathy K, Berndt M, Castel A, et al. Carbonation of a blended slag-fly ash geopolymer concrete in field conditions after 8 years. Construction and Building Materials. 2016;125:661-669.

7. Gajda J, Miller FM. Concrete as a Sink for Atmospheric Carbon Dioxide: a Literature Review and Estimation of $\mathrm{CO}_{2}$ Absorption by Portland Cement Concrete. PCA, Chicago, USA. 2000.

8. Yang KH, Seo EA, Tae SH. Carbonation and $\mathrm{CO}_{2}$ uptake of concrete. Environmental Impact Assessment Review. 2014;46:43-52.

9. Nässén J, Hedenus F, Karlsson S, et al. Concrete vs. wood in buildings: an energy system approach. Building and Environment. 2012;51:361-369.

10. Gajda J. Absorption of Atmospheric Carbon Dioxide by Portland Cement PCA. R\&D, Chicago, USA. 2001.

11. Cui H, Tang W, Liu W, et al. Experimental study on effects of $\mathrm{CO} 2$ concentrations on concrete carbonation and diffusion mechanisms. Construction and Building Materials. 2015;93:522-527.

12. Jedidi M, Abroug A, Moalla B. Non-destructive Testing for the Diagnosis and Repair of a Reinforced Concrete Building. International Journal of Architecture, Engineering and Construction. 2017;6(1):20-28.

13. RILEM Committee TC56. Measurement of hardened concrete carbonation depth -CPC 18. Materials and Structures. 1988;21(126):453-455.

14. Jiang L, Lin BY, Cai Y. A model for predicting carbonation of high-volume fly ash concrete. Cement and Concrete Research. 2000;30(5):699-702.

15. Ceukelaire LD, Nieuwenburg VD. Accelerated carbonation of a blast-furnace cement concrete. Cement and Concrete Research. $1993 ; 23(2): 442-452$.

16. Canadian Journal of Civil Engineering. Special Issue on Alkali-Aggregate Reactivity. 2000;27(2)
17. Standard: CSA A23.1-00/A23.2-00. Concrete Materials and Methods of Concrete Construction/Methods of Test for Concrete. CSA International, 178 Rexdale Boulevard, Toronto, ON, M9W 1R3, 2000. pp. 360 .

18. LCPC. Recommandations pour les préventions des désordres dus à l'alcali-réaction. Guide technique. 1994.

19. Thomas MDA, Shehata MH, Sashiprakash SG, et al. Use of Ternary Cementitious Systems Containing Silica Fume and Fly Ash in Concrete. Cement and Concrete Research. 1999;29(8):1207-1214.

20. Tepponen P, Eriksson BE. Damages in concrete railway sleepers in Finland. Nordic Concrete Research. 1987;6:199-209.

21. Heinz D, Ludwig U, Rudiger I. Delayed ettringite formation in heat treated mortars and concretes. Betonwerk und Fertigteil-Technik. 1989;55(11):56-61.

22. Shayan A, Quick GW. Microscopic features of cracked and uncracked concrete railway sleepers. International Concrete Abstracts Portal. 1992;89(4):348-361.

23. Mielenz RC, Marusin SL, Hime WG, et al. Investigation of prestressed concrete railway tie distress. Concrete International. 1995;17(12):62-68.

24. Sahu S, Thaulow N. Delayed ettringite formation in swedish concrete railroad ties. Cement and Concrete Research. 2004;34(9):1675-1681.

25. Hime WG. Delayed ettringite formation- a concern for precast concrete?. PCI Journal. 1996;41(4):26-30.

26. Hobbs DW. Cracking of concrete attributed to delayed ettringite formation. Proceedings of the eleventh annual $\mathrm{BCA} /$ concrete society conference on higher education and the concrete industry, UMIST, Manchester, UK. 2001;6:51-60.

27. Ozol MA, Strand W. Delayed ettringite formation at Brewer Stadium, Boone, North Carolina. Cement concrete and aggregate. 2000;22(1):24 34.

28. Collepardi M. Damage by delayed ettringite formation. Concrete international. 1999;21(1):69-74. 